\title{
BAD FORUM SHOPPING Y RECURSO DE REVISIÓN: \\ "CAUSA CAUSAE EST CAUSA CAUSATI" \\ (STS DE 25 DE NOVIEMBRE DE 2019)
}

\author{
BAD FORUM SHOPPING AND JUDICIAL REVIEW: \\ "CAUSA CAUSAE EST CAUSA CAUSATI" \\ (STS DE 25 DE NOVIEMBRE DE 2019) \\ DECISION OF THE SUPREME COURT OF NOVEMBER 25, 2019
}

\author{
Pilar JuÁrez Pérez \\ Profesora Titular de Derecho Internacional Privado \\ Universidad Carlos III de Madrid \\ ORCID ID: 0000-0003-3044-5679
}

Recibido: 16.03.2020/ Aceptado: 05.04.2020

DOI: https://doi.org/10.20318/cdt.2020.5653

\begin{abstract}
Resumen: Se solicita la revisión, ex art. $510.4^{\circ}$ LEC, de una sentencia de divorcio ganada injustamente en virtud de maquinación fraudulenta, al ocultar y falsear intencionadamente el actor los datos del domicilio de la esposa demandada, declarada en situación de rebeldía procesal. El TS no entra en el fondo del asunto, al declarar la caducidad de la acción de revisión, por haber transcurrido más de tres meses desde el descubrimiento del fraude (art. 512 LEC). Antes del proceso desarrollado en España, se sustanciaba en Nueva Jersey (EE.UU.) un procedimiento con el mismo objeto y entre las mismas partes. Pese a lo cual, el marido presenta en una segunda demanda de divorcio ante el Juzgado de Primera Instancia, donde realiza el fraude descrito. Surge la cuestión de cómo pudo abrirse en España un segundo proceso estando pendiente el primero. La respuesta está en una institución sobradamente conocida en el Derecho internacional privado: el forum shopping.
\end{abstract}

Palabras clave: forum shopping, exequátur, sentencia extranjera de divorcio, maquinación fraudulenta, «recurso» de revisión.

Abstract: This judgement by the Supreme Court resolves an application for review of sentence based on the ground for opposition referred to in Article $510.4^{\circ}$ of the Code of Civil Procedure (CCP): an unfair judgement caused by malicious conduct. The plaintiff intentionally concealed and distorted the information about defendant's domicile; as a result, the judgment was given by default. The Court did not examine the substantive matter and declares the expiration of the review action, because more than three months had passed since the fraud was discovered (Art. 512 CCP). Before the procedure in Spain an identical process was taking place in New Jersey (USA). The question that arises is how a second process could be opened in Spain while the first was pending. The answer lies in a well-known institution of Private International Law: forum shopping.

Keywords: forum shopping, exequatur, foreign sentence of divorce, fraudulent machination, judicial review. 
Sumario: I. El supuesto de hecho: un divorcio y dos jurisdicciones. II. El forum shopping: «causa causae est causa causati». III. Corolario: no es la institución (forum shopping), es la utilización (mala fe procesal).

\section{El supuesto de hecho: un divorcio y dos jurisdicciones.}

1. La sentencia del Tribunal Supremo de 25 de noviembre de 2019 que aquí se analiza deriva de los hechos que relatamos a continuación ${ }^{1}$. Se sustancia proceso de divorcio entre nacionales españoles ante un tribunal de New Jersey (EE.UU.), lugar de residencia de la esposa. Con anterioridad a la finalización del procedimiento por sentencia, el marido presenta nueva demanda de divorcio ante un Juzgado de Primera Instancia de La Coruña, sin realizar mención alguna al proceso pendiente en Estados Unidos y omitiendo la verdadera dirección de la demandada y de las hijas comunes de ambos, que residían con su madre en aquel país. Como consecuencia, sobre el mismo vínculo recaen finalmente dos sentencias de disolución matrimonial: la primera, dictada en abril de 2015 por el tribunal de New Jersey; la segunda, en mayo del mismo año por el tribunal español.

2. La resolución española se dicta en rebeldía, debido a que el demandante, pese a tener conocimiento del domicilio correcto de su esposa e hijas en Estados Unidos, no facilitó al Juzgado dicha información, comunicando en cambio un domicilio que se encontraba deshabitado desde 2010. Al mismo tiempo, ocultó al órgano judicial la existencia de un domicilio en España de los padres de la demandada, cuyos datos conocía, imposibilitando su la citación en el proceso, e impidiéndole tener conocimiento de su inicio.

3. En 2019, esta circunstancia la lleva a solicitar al Tribunal Supremo la revisión de la sentencia de divorcio así dictada, sobre la base de los artículos 509 y 510 LEC $^{2}$. El primero determina los órganos competentes para conocer del recurso de revisión, y las resoluciones susceptibles del mismo, cuya firmeza se requiere. Por su parte, el artículo 510 LEC recoge catálogo de causas legales para instar la revisión $n^{3}$, alegándose en el presente caso la concurrencia del motivo $4^{\circ}$ : "Si se hubiere ganado injustamente en virtud de cohecho, violencia o maquinación fraudulenta".

4. En opinión de la recurrente, concurría este motivo de revisión dado que el demandante en el proceso de origen había sido perfectamente conocedor de su domicilio y el de sus hijas cuando facilitó al Juzgado, a efectos de notificaciones del proceso, una dirección que le constaba desactualizada y que además, al no residir nadie, no podía servir de punto de partida para localizar su paradero, como sí hubiera ocurrido de haber facilitado el demandante la dirección de sus padres, que también conocía. Habiendo sido declara en rebeldía por este motivo, la recurrente no pudo articular en el proceso una defensa adecuada a sus intereses, dictándose una sentencia contraria a los mismos y favorable a su ex marido como consecuencia de sus maquinaciones fraudulentas para ocultar el domicilio real de la demandada. A mayor abundamiento, subrayaba la recurrente el hecho de que el demandante había instado un segundo proceso de divorcio en España estando pendiente un procedimiento en Estados Unidos, ocultando también esta circunstancia al Juzgado de Primera Instancia.

\footnotetext{
${ }^{1}$ RJ $2019 \backslash 4967$.

2 Artículo 510 redactado por el apartado trece de la disposición final cuarta de la L.O. 7/2015, de 21 de julio, por la que se modifica la L.O. 6/1985, de 1 de julio, del Poder Judicial (B.O.E. núm. 174, de 22 de julio de 2015). En vigor desde el 1 de octubre de 2015. Sobre esta reforma y los motivos que la originaron, vid. D. LóPEZ GARRIDO, "El carácter vinculante de la jurisprudencia del Tribunal Europeo de Derechos Humanos respecto de las sentencias judiciales firmes: la reforma del recurso de revisión por la Ley Orgánica 7/2015, de 21 de julio, y la Ley 41/2015, de 5 de octubre”, Parlamento y Constitución. Anuario, Núm. 18, 2017, pp. 55-78, esp. pp. 66-69 y 72-73.

${ }^{3}$ Catálogo que tiene la condición de numerus clausus y que debe ser siempre objeto de una interpretación restrictiva, como ha reiterado la jurisprudencia del Tribunal Supremo (entre otras muchas, SSTS de 15 de marzo de 2001, RJ 2000\1265; de 26 de abril de 2005, RJ 2005\6418; de 24 de mayo de 2005, RJ 2005\9658; de 31 de octubre de 2005, RJ 2006\125; de 15 de febrero de 2007, RJ 2007\7372; de 21 de diciembre de 2012, RJ 2012\11281).
} 
5. Así planteado el recurso -cuya estimación interesó el Ministerio Fiscal-, el demandado de revisión arguyó en su defensa que la recurrente tenía conocimiento de la existencia de la sentencia española de divorcio desde mucho tiempo antes de presentar el recurso de revisión ante el Tribunal Supremo. En concreto, el 30 de enero de 2018 había obtenido del Registro Civil un certificado literal de matrimonio donde aparecía anotado el divorcio decretado por la sentencia española posteriormente recurrida. La recurrente había solicitado dicha certificación en el marco de las actuaciones preprocesales dirigidas a la presentación de una demanda de exéquatur de la sentencia norteamericana. En consecuencia, el demandado alegaba que el fraude que la recurrente afirmaba producido durante el proceso de divorcio sustanciado en España, había sido conocido por ella desde que obtuvo la certificación literal de matrimonio y la aportó con la solicitud de exequátur, un año antes de la solicitud de revisión.

6. Al examinar el recurso, el Tribunal Supremo no llega a entrar en el fondo del asunto, dejando inexplorada la cuestión de si hubo o no maquinación fraudulenta en la actuación del demandante en el proceso de origen. Con carácter previo a este -eventual- análisis, examina la alegada caducidad de la acción de revisión, determinando su concurrencia y desestimando por tanto el recurso sin ulteriores consideraciones. Como fundamente jurídico, el artículo 512 LEC, que establece un doble plazo de cara a la interposición del recurso de revisión, siendo preceptivo el cumplimiento de ambos para su admisión. Así, el párrafo $1^{\circ}$ fija taxativamente un plazo general de cinco años: "En ningún caso podrá solicitarse la revisión después de transcurridos cinco años desde la fecha de la publicación de la sentencia que se pretende impugnar. Se rechazará toda solicitud de revisión que se presente pasado este plazo".

7. En el presente supuesto, la recurrente sí se encontraba dentro de dicho período, por lo que fue el incumplimiento del segundo requisito temporal el que motivó la desestimación. Éste se recoge en el párrafo $2^{\circ}$ del mismo precepto, y dentro del plazo general de cinco años, fija otro específico, cuyo dies a quo se activa en el momento en que se tiene conocimiento de la circunstancia que ha motivado la interposición del recurso: “(...), se podrá solicitar la revisión siempre que no hayan transcurrido tres meses desde el día en que se descubrieren los documentos decisivos, el cohecho, la violencia o el fraude, o en que se hubiere reconocido o declarado la falsedad".

8. Considerando acreditado que la recurrente había rebasado el plazo específico de tres meses consagrado por el artículo 510.2 LEC, el Tribunal recuerda que estamos ante "un estricto plazo de caducidad que, junto al general de cinco años [establecido en el párrafo anterior], viene a limitar temporalmente la posibilidad de instar la revisión como medio de carácter extraordinario y excepcional frente a la eficacia de sentencias firmes", lo que en el supuesto de autos conduce inexorablemente a rechazar la demanda de revisión.

9. Además de la normativa citada, el fundamento jurídico de esta decisión radica en la propia jurisprudencia del Tribunal Supremo en interpretación del recurso de revisión. Siendo la cosa juzgada el eje fundamental de la seguridad jurídica, concibe el Tribunal este recurso como un remedio extraordinario que, sólo de forma muy excepcional, y en plazos muy rígidamente tasados, permite destruir dicho eje fundamental. Se trata de un proceso de naturaleza extraordinaria, que constituye una excepción al principio esencial de la irrevocabilidad de las sentencias que hayan adquirido firmeza. Por tanto, "la interpretación de los casos que lo enmarcan debe efectuarse con un criterio sumamente restrictivo ya que, en caso contrario, el principio de seguridad jurídica proclamado en el artículo 9.3 de la Constitución quedaría vulnerado y se provocaría una quiebra del principio procesal de la autoridad de la cosa juzgada"4.

10. En sentido estricto, la revisión no es un «recurso», sino un mecanismo de rescisión de la cosa juzgada, "una pretensión impugnativa de la sentencia firme sobre una base fáctica nueva y diferente de

${ }^{4}$ STS núm. 88/2018, de 15 de febrero (RJ 20188\472); ATS de 19 de diciembre de 2019 (JUR $2020 \backslash 6107$. 
la que fue tratada en el proceso anterior" ${ }^{\prime}$. En consecuencia, constituye un proceso o juicio autónomo 6 , no una nueva instancia del proceso sometido a ella, y no permite un nuevo enjuiciamiento de las cuestiones ya debatidas y resueltas en él ${ }^{7}$.

11. Cerrada así definitivamente la posibilidad de rescindir la cosa juzgada que constituye la sentencia del Juzgado de Primera Instancia, esta decisión del Tribunal Supremo constituye un motivo de reflexión sobre el origen último de esta situación de dualidad de procesos idénticos sustanciados paralelamente en dos países distintos: la figura del forum shopping.

\section{El forum shopping: «causa causae est causa causati»}

12. Afirmó Santo Tomás de Aquino: «causa causae est causa causati» (Quaestiones Disputatae, 3,1). Haciéndose eco, un adagio del Derecho penal sostiene que «el que es causa de la causa, es causa del mal causado», lo que constituye una base teórica para la imputación de la responsabilidad criminal. Extrapolando este razonamiento al ámbito del Derecho internacional privado, es factible encontrar en el fenómeno del forum shopping, la causa última de situaciones como la que aquí se nos plantea.

13. El supuesto descrito constituye un emblemático ejemplo de la práctica conocida como bad forum shopping, que no es sino la utilización fraudulenta o abusiva de las reglas habituales de la competencia judicial internacional, que con frecuencia permiten acudir a más de una jurisdicción estatal para demandar la resolución de un mismo asunto. Es la consecuencia natural de tres de los rasgos que caracterizan al Derecho internacional privado: la exclusividad, la estatalidad y la relatividad.

14. En virtud de la primera, al resolver cuestiones jurídicas sometidas a su conocimiento, los tribunales de cada Estado determinan su competencia -o falta de ella- únicamente en base a sus propios foros, sin atender a lo que sobre el mismo asunto puedan establecer los criterios competenciales de otros países. Como consecuencia, en la práctica resulta frecuente que un mismo litigio sea susceptible de ser sometido a varias jurisdicciones estatales diferentes; o por el contrario, ninguna se considere competente para resolverlo, siempre según sus propias y exclusivas normas de competencia judicial internacional. En el presente caso, este uso excluyente de los propios foros fue lo que propició que un mismo proceso de divorcio fuera sometido, sucesivamente, al conocimiento de los tribunales estadounidenses y españoles, que pudieron declararse competentes para resolverlo en virtud de sus respectivos criterios competenciales.

15. Por su parte, la estatalidad del Derecho internacional privado deriva del hecho de que esta disciplina constituye una rama más del ordenamiento jurídico de cada país. Corresponde a cada Estado delimitar sus propias normas, que aplicarán de forma exclusiva sus tribunales estatales, lo que invariablemente conduce a que sobre un mismo asunto puedan recaer percepciones jurídicas diferentes o emitirse pronunciamientos distintos en cada Estado. Ésta es la denominada relatividad del Derecho internacional privado, que ocasiona la existencia de soluciones jurídicas diversas en función del país desde el que se enjuicie el asunto. Como es obvio, ello genera en los particulares una considerable inseguridad jurídica, consecuencia que tratan de paliar los Estados mediante la elaboración de textos legales internacionales de unificación de normas de Derecho internacional privado ${ }^{8}$. Correlativamente, esta misma

\footnotetext{
${ }^{5}$ STC núm. 158/1987, de 20 de octubre (RTC 1987\158).

${ }^{6}$ STS núm. 288/1988, de 18 de marzo (RJ 1998\2043).

7 STSJ de Navarra núm. 4/2003, de enero 2003 (RJ 2003\2218).

${ }^{8}$ Pero, como bien señala J. SudEROw, ni siquiera dichas herramientas logran eliminar completamente tal inseguridad jurídica, como gráficamente ejemplifica el supuesto de las cláusulas de elección de ley contenidas en tales instrumentos: "como el Derecho Internacional Privado de cada Estado y la interpretación de las cláusulas de jurisdicción puede ser diferente, las cláusulas de jurisdicción adolecen de cierta inseguridad respecto a su interpretación y determinación de la jurisdicción de la propia disputa" ("Cuestiones de jurisdicción internacional en torno a la aplicación privada del Derecho antitrust: fórum shopping y «demandas torpedo»”, Cuadernos de Derecho Transnacional, octubre 2010, Vol. 2, No 2, p. 321).
} 
relatividad de soluciones en la práctica se convierte en una herramienta al servicio de los particulares intereses de cada individuo, que habrá de valorar cuál es el Estado más propicio para obtener una decisión que le sea favorable.

16. Desde una perspectiva procesal, la conjunción de estas tres características da lugar al fenómeno denominado forum shopping, expresión que objetivamente designa la posibilidad de que existan varios tribunales estatales competentes para conocer de un mismo asunto; y subjetivamente, la facultad que ello otorga a los particulares de elegir el que más convenga a sus intereses. Una elección directamente vinculada al derecho aplicable al fondo del asunto, pues el sujeto acudirá al tribunal cuyo sistema de conflicto de leyes le facilite el acceso al ordenamiento que resulte más favorable a su pretensión.

17. Esta multiplicidad de jurisdicciones competentes suele venir ocasionada por la diferencia de sistemas estatales de competencia judicial internacional, como se ha dicho; pero también, por la acción del legislador comunitario, que en ocasiones articula sus sistemas competenciales sobre un amplio abanico de foros, que evidencia una considerable generosidad al otorgar a los particulares múltiples opciones de litigar. En el ámbito material que nos ocupa, cabe citar como ejemplo de esta inclinación comunitaria a la multiplicación de las jurisdicciones competentes el régimen contenido en el Reglamento 2201/2003, de 27 de noviembre, relativo a la competencia, el reconocimiento y la ejecución de resoluciones en materia matrimonial y de responsabilidad parental ${ }^{9}$. El texto establece un sistema de foros de competencia puramente alternativos, no sometidos a una relación de jerarquía, cuya utilización efectiva se deja a la autonomía de la voluntad del demandante, al que se ofrecen múltiples opciones de litigar (art. 3) ${ }^{10}$.

18. De este modo, se deja en manos del demandante la designación de un concreto tribunal al que someter su pretensión, entre todos los que potencialmente resultan competentes, bien por como consecuencia de sus respectivas normas estatales o bien por efecto de las reglas comunitarias aplicables al caso. Esta capacidad de elección del demandante se materializa a través de la interposición de la demanda, introduciéndose el matiz subjetivo cuando se considera que la parte designa uno u otro tribunal en función de su presunta favorabilidad a sus pretensiones, en aplicación de una determinada ley sustantiva y/o procesal ${ }^{11}$. A priori, se trata de una situación perfectamente legítima, que responde al deseo del legislador de otorgar al particular la máxima protección procesal posible, permitiéndole acceder a más de una jurisdicción para reclamar la tutela de sus intereses.

19. Cada legislador -incluido el comunitario- dibuja el mapa de su ámbito jurisdiccional mediante el establecimiento de un conjunto de foros de competencia judicial internacional, que otorgan previsibilidad (ergo, seguridad jurídica) a las partes, que pueden conocer de antemano cuáles son sus posibilidades de litigar ante un eventual conflicto ${ }^{12}$. En España, los foros de competencia judicial internacional están inspirados además en el principio de proximidad o vinculación mínima ${ }^{13}$. En virtud del

\footnotetext{
${ }^{9}$ DOUE núm. 338, de 23 de diciembre de 2003.

${ }^{10}$ Como advierten A.L. Calvo Caravaca y J. Carrascosa, GonzÁlez, la consecuencia resulta obvia: "al existir nada más y nada menos que siete foros de competencia judicial internacional en materia de divorcio (...) es habitual que los cónyuges presenten sus demandas antes tribunales de distintos Estados miembros, todos ellos competentes para conocer del litigio ex artículo 3 RB II-bis" (Derecho Internacional Privado, volumen II, 18 a ed., Comares, Granada, 2018, p. 245). Consciente de ello, y a fin de paliar los negativos efectos de esta multiplicidad de foros, el propio legislador articula mecanismos para combatirlos y/o minimizarlos, como son la regulación de la litispendencia internacional, el establecimiento de un sistema generoso de reconocimiento de resoluciones judiciales, o la unificación de las normas de conflicto aplicables, de forma que la respuesta sustantiva de los distintos tribunales sea coincidente.

${ }^{11}$ A. Calvo Caravaca y J. Carrascosa González, Derecho Internacional Privado, volumen I, $18^{\mathrm{a}}$ ed., Comares, Granada, 2018 , p. 15

12 SSTJUE de 19 de abril de 2012, C-523/10, Wintersteiger AG y Products $4 U$ Sondermaschinenbau GmbH, (ECLI:EU:C:2012:220); y de 25 de octubre de 2011, asuntos acumulados C- 509/09 y C-161/10, eDate Advertising GmbH y X y Olivier Martinez, Robert Martinez y MGN Limited (ECLI:EU:C:2011:685).

${ }^{13}$ Principio que, con carácter general, aspira a asegurar «el equilibrio entre demandante y demandado» (S. CLAVEL, Droit international privé, $5^{\mathrm{e}}$ éd., Dalloz, Paris, 2018, p. 170.)
} 
cual, la base teleológica de toda competencia es la directa relación del asunto con la jurisdicción española, ya sea de forma objetiva o subjetiva. El primer caso se da cuando concurre en el litigio uno o varios elementos conectados con el sistema jurídico español; habitualmente, la nacionalidad o la residencia de alguna de las partes; pero también pueden darse otras circunstancias, como el lugar de producción del daño, en materia de responsabilidad extracontractual, o de celebración del contrato, en la relación individual de trabajo. Asimismo, la vinculación puede tener carácter subjetivo cuando deriva de la autonomía de la voluntad del demandante o de ambas partes, que acuerdan voluntariamente someter su litigio a la jurisdicción española, aun cuando no concurra en él ningún otro elemento vinculado a ella. Consciente de las implicaciones de esta elección, el sistema estatal español limita su uso al cumplimiento de ciertas condiciones, siendo la más reseñable la que exige que se trata de una materia disponible para las partes ${ }^{14}$.

20. En todo caso, lo que resulta irrenunciable es la exigencia de una mínima relación entre el litigio y los tribunales españoles, siendo esta vinculación la base de su competencia, aunque luego se positivice en muy diversos foros de competencia. La importancia de esta cuestión deriva de su estrecha relación con el derecho a un proceso equitativo (artículo $6 \mathrm{CEDH}$ ) y a la tutela judicial efectiva (artículo $24 \mathrm{CE}$ ). Su salvaguarda exige un sistema de foros basados en la idea de proximidad y vinculación, de forma que a los particulares les resulte previsible y económicamente asequible el planteamiento de un litigio $^{15}$. Y a contrario, la falta absoluta de relación entre el tribunal que conoce y el asunto a él sometido puede constituir un ejemplo de foro exorbitante, sin justificación teleológica alguna, y carente de fundamento constitucional ${ }^{16}$.

21. Desde un punto de vista material, el forum shopping también puede constituir una herramienta útil para lograr "la aplicación de un mejor derecho sustantivo que devenga en una mejor solución del fondo del asunto y no únicamente ventajas meramente procesales" ${ }^{17}$. Esta justificación, como las anteriores, despoja al fenómeno de toda connotación negativa o censurable, convirtiéndolo en un mecanismo adecuado y beneficioso para la obtención de una respuesta judicial previsible, adecuada y cercana a cada concreta situación privada internacional.

22. Así configurado cada sistema estatal de competencia judicial internacional, cuando concurre un elemento extranjero, las relaciones entre particulares tienen el efecto de poner en contacto dichos sistemas procesales, generando una considerable multiplicidad de foros susceptibles de dar acceso a distintos tribunales estatales. En el presente supuesto concurrían la nacionalidad española y el domicilio norteamericano como factores de apertura de ambas jurisdicciones, activando sus respectivos foros de competencia judicial en materia de divorcio para poder pronunciarse sobre la disolución del vínculo.

23. A menudo, a este factor de apertura que por sí solas constituyen las relaciones privadas internacionales se suma el favorecimiento legislativo del forum shopping, tendencia de la que el ordena-

\footnotetext{
${ }^{14}$ Artículo 22 bis LOPJ: "En aquellas materias en que una norma expresamente lo permita, los Tribunales españoles serán competentes cuando las partes (...) se hayan sometido expresa o tácitamente a ellos" (el subrayado es nuestro).

${ }^{15}$ Como recuerda el Tribunal de Justicia, este objetivo de seguridad jurídica permite "al mismo tiempo al demandante determinar fácilmente el órgano jurisdiccional ante el cual puede ejercitar una acción, y al demandado prever razonablemente ante qué órgano jurisdiccional puede ser demandado" (STJUE de 25 de octubre de 2012, C-133/11, Folien Fischer AG, Fofitec AG y Ritrama SpA, ECLI:EU:C:2012:664). Con anterioridad, en el mismo sentido, SSTJUE de 13 de julio de 2006, C-103/05, Reisch Montage AG y Kiesel Baumaschinen Handels GmbH (ECLI:EU:C:2006:471); de 7 de mayo de 2007, C-386/05, Color Drack GmbH y Lexx International Vertriebs GmbH (ECLI:EU:C:2007:262); de 23 de abril de 2009, C-533/07, Falco Privatstiftung, Thomas Rabitsch y Gisela Weller-Lindhorst (ECLI:EU:C:2009:257); y de 17 de noviembre de 2011, C-327/10, Hypotečni banka a.s. y Udo Mike Lindner (ECLI:EU:C:2011:745).

${ }^{16}$ En este sentido, más allá se pronuncia F. J. Garcimartín Alférez, al defender que "si el vínculo [que asienta la competencia judicial internacional de los tribunales españoles] es manifiestamente irrazonable, la norma es inconstitucional” "“Caben reducciones teleológicas o abuso de derecho en las normas sobre competencia judicial internacional?", Revista Española de Derecho Internacional, 1995 (II), vol. XLVII, p. 123).

${ }^{17}$ A. Aguilar Domínguez, "La delgada línea entre el forum shopping y el fraude a la ley", Revista de Derecho Privado, Cuarta Época, año 5, número 13, enero-junio 2018, p. 86.
} 
miento comunitario constituye un ejemplo muy representativo. En esta línea, cabe recordar el concepto tripartito de domicilio del demandado recogido en el Reglamento 1215/2012, de 12 de diciembre (art. 63), que aumenta exponencialmente las posibilidades de litigar; o, sin salir del mismo texto legal, la regla del litisconsorcio (art. 8.1), que permite al demandante elegir el tribunal del Estado miembro donde tenga su domicilio cualquiera de los codemandados ${ }^{18}$.

24. Vemos, por tanto, cómo el fenómeno de la multiplicidad de jurisdicciones para litigar no sólo es una consecuencia natural e inevitable de la propia esencia del Derecho internacional privado: estatalidad, exclusividad, relatividad. Además, en ocasiones es el propio legislador quien busca y provoca su existencia, en la convicción de que, a mayores posibilidades de elección de tribunal, mejor y menos costosa justicia podrán obtener los particulares.

25. Axiológicamente, el forum shopping no constituye un fenómeno censurable o nocivo desde la perspectiva de la buena administración de justicia. Lo que sí resulta reprochable y dañino es el uso que de esta libertad de elección procesal pueden llegar a hacer los particulares, del que el supuesto abordado por la sentencia del Tribunal Supremo de 25 de noviembre de 2019 constituye un ejemplo lamentablemente ilustrativo. No es admisible que la facilidad de acceso a los tribunales -instrumentalizada en términos de amplitud de opciones para litigar- se utilice para provocar una dualidad de procesos, que en la práctica puede conducir a la existencia de sentencias inconciliables, y a la aparición de situaciones claudicantes, tan indeseadas como irresolubles.

26. Es, por tanto, la mala fe del litigante, materializada en la figura del fraude procesal, la que convierte el forum shopping en una herramienta censurable y nociva. En realidad, estamos ante un mal uso de esta institución, que en absoluto está concebida para permitir o facilitar la reiteración de un proceso, sino para aumentar las opciones de litigar de las partes, en aras de la mejor administración de justicia y la reducción de costes procesales. Todo lo contrario de lo que provoca aquí el demandante al reproducir su petición ante los tribunales españoles, estando ya pendiente en New Jersey, pues ello no sólo ha de generar la situación claudicante descrita, sino que supone un considerable encarecimiento de los costes de litigación.

27. A esta reprochable actuación se añade en el presente caso la ocultación maliciosa del domicilio de la demandada, evitando así su personación en el proceso y limitando con ello de facto sus posibilidades de defensa. Entramos aquí de lleno en la causa legal para interponer el recurso de revisión (art. 510.4 ${ }^{\circ}$ LEC), definiendo el Tribunal Supremo esas «maquinaciones fraudulentas» como "todo artificio realizado personalmente o con auxilio de engaño por la parte que haya obtenido la sentencia deseada, o por quienes la representen, que implique una conducta o actuación maliciosa, causante de indefensión" $" 19$.

28. Un comportamiento que resulta especialmente grave en este supuesto, puesto que como subraya el Alto Tribunal, la actuación de mala fe del actor existe ya simplemente cuando existe una falta de diligencia del actor en la localización de un domicilio donde emplazar personalmente al demandado; tanto más cuando lo que se produce es una ocultación de datos sobre el domicilio de éste o el señala-

\footnotetext{
${ }^{18}$ Como ejemplo de una utilización fraudulenta de esta posibilidad (bad forum shopping), vid. la STS núm. 24/2017, de 10 de enero (ECLI: ES:TS:2017:24), que aplica la doctrina comunitaria que rechaza la posibilidad de utilizar el foro de conexidad de forma fraudulenta, como la consistente en crear o mantener de forma artificial las condiciones de aplicación de esa disposición en el momento de ejercitarse la acción (STJUE de 21 de mayo de 2015, asunto C-352/13, Cartel Damage Claims (CDC) Hydrogen Peroxide SA y Akzo Nobel NV, Solvay SA/NV, Kemira Oyj, FMC Foret, S.A., ECLI:EU:C:2015:335; STJUE de 1 de diciembre de 2011, C-145/10, Eva-Maria Painer y Standard VerlagsGmbH, Axel Springer AG, Süddeutsche Zeitung GmbH, Spiegel-Verlag Rudolf Augstein GmbH \& Co KG, Verlag M. DuMont Schauberg Expedition der Kölnischen Zeitung GmbH \& Co KG, ECLI:EU:C:2011:798).

19 SSTS núm. 10/1996, de 14 de enero (RJ 1997\114); núm. 289/1996, de 15 de abril (RJ 1996\3088); núm. 985/1995, de 8 de noviembre (RJ 1995\8639); núm. 729/1993, de 30 de junio (RJ 1993\5227).
} 
miento "de un domicilio dónde el actor sabe que no se va a encontrar al notificado, a los efectos de que no se haga la notificación en forma personal sino mediante la publicación de los edictos"20.

29. Desde el punto de vista de la competencia judicial internacional, esta actuación fraudulenta tuvo además una consecuencia de especial gravedad, en absoluto desdeñable: al hurtar el conocimiento del segundo litigio a la demandada, el actor la despojó no sólo de sus posibilidades de defensa en el proceso, sino también de la posibilidad de solicitar su suspensión mediante la interposición de la declinatoria internacional (art. 63 LEC).

30. En efecto, para el sistema procesal español la litispendencia internacional constituye un motivo de suspensión de un procedimiento iniciado en España, sujeto a valoración judicial y a la concurrencia de los requisitos establecidos en el artículo 39.1 de la Ley 29/2015, de 30 de julio, de Cooperación Jurídica Internacional en Materia Civil ${ }^{21}$. Estas condiciones son cumulativas y exigen que el órgano extranjero esté conociendo en virtud de un foro razonable, que la resolución que eventualmente emita sea susceptible de reconocimiento en España, y que la suspensión del procedimiento se considere necesaria en aras de la buena administración de justicia.

31. Cumplidos dichos requisitos el tribunal español valorará si procede o no la suspensión del proceso iniciado posteriormente en España, teniendo posibilidad de acordar su continuación si concurre alguna de estas circunstancias: el sobreseimiento o suspensión del procedimiento en el extranjero, la excesiva dilatación en el tiempo del desarrollo de dicho procedimiento, la improbabilidad de que la sentencia emitida en el tercer Estado pueda ser reconocida en España, o la necesidad de reanudar el proceso en España en aras de la buena administración de justicia.

32. Este mecanismo contenido en la ley procesal española constituye un significativo avance en la eliminación de los efectos negativos del forum shopping, cuales son la duplicidad de procesos y la eventual inconciliabilidad de decisiones, con la consecuente situación claudicante, que desplegará diferentes efectos jurídicos según el Estado desde el que se enjuicie. Entre otras consecuencias, la censurable actuación del actor en el proceso desarrollado en España, provocando la rebeldía de la demandada, la privó también de este mecanismo de defensa, circunstancia que resulta obligado subrayar por cuanto hubiera podido propiciar un resultado material radicalmente distinto.

33. Por lo que respecta al legislador español, hay que reiterar su coherente y eficaz actuación en este ámbito, al instaurar un sistema -la suspensión del proceso por litispendencia internacional- que permita minimizar las eventuales consecuencias negativas del forum shopping, sin necesidad de restringirlo excesivamente. De esta forma, permanecen intactas las posibilidades de litigar de los interesados, pero se les permite intentar detener dichos efectos negativos cuando exista una mala utilización por alguna de las partes de esta amplitud de opciones procesales.

\section{Corolario: no es la institución (forum shopping), es la utilización (mala fe procesal)}

34. Desde una perspectiva procesal, la decisión aquí analizada suscita dos reflexiones: sobre el «recurso» de revisión y sobre el forum shopping. Respecto a la primera, llama poderosamente la atención -y resulta censurable- que el legislador español someta la acción de revisión a un estricto y

\footnotetext{
${ }^{20}$ En este sentido, vid. I.J. CuBillo LóPEz, Los actos de comunicación del tribunal con las partes, Tesis Doctoral, Universidad Complutense de Madrid, 1999, esp. pp. 191-192.

${ }^{21}$ BOE núm. 182, de 31 de julio de 2015. Sobre la introducción de la litispendencia internacional en el sistema procesal español, vid. A. Rodríguez Benot, "La Ley de Cooperación Jurídica Internacional en Materia Civil”, Cuadernos de Derecho Transnacional, marzo 2016, Vol. 8, No 1, esp. pp. 234-259; M. Gardeñes Santiago, "Procedimientos paralelos en España y en el extranjero: el Título IV de la Ley 29/2015, de 30 de julio", Revista Española de Derecho Internacional, Vol. 68/1, enerojunio 2016, pp. 109-119.
} 
reducido plazo de caducidad, cuyo transcurso convierte en inatacable una sentencia obtenida mediante maquinaciones fraudulentas. Ello es tanto como sacrificar la justicia material y efectiva que implica sancionar una actuación maliciosa, en aras de la seguridad jurídica que puede suponer tener una sentencia inexpugnable, aunque esta sentencia se haya "ganado injustamente" (art. 510.4 LEC).

35. Un error, por consolidado e inatacable, no deja de ser un error; una sentencia injustamente ganada no deja de serlo por más años que pasen. Al igual que la nulidad no caduca ni prescribe -lo hace su acción-, tampoco debería hacerlo la posibilidad de subsanar el error y sancionar la conducta maliciosa que lo ha provocado. Creemos, con Gimeno SENDRA, que "el fundamento de la revisión es la exigencia constitucional de que la tutela judicial sea efectiva y que (...) se otorgue la razón a quien efectivamente la tiene, dentro y fuera del proceso, y no a quien ha sabido moverse en él con malas artes, insidias o enredos" 22 . La eficacia real de este objetivo queda considerablemente mermada por su sometimiento al plazo legal general de cinco años y específico de tres meses, aun cuando objetivamente concurra una justificación para dicha restricción temporal: la «sacrosanta» cosa juzgada ${ }^{23}$. Quede aquí apuntada esta reflexión, que en absoluto implica ignorancia del hecho de que el Tribunal Constitucional ha declarado y avalado la constitucionalidad de la limitación temporal del recurso de revisión ${ }^{24}$.

36. La segunda reflexión va dirigida al fenómeno del forum shopping, tanto si es consecuencia de las propias características del Derecho internacional privado, como si es expresamente provocado por la acción del legislador. En todo caso, compartimos plenamente la opinión de los profesores CALVO Caravaca y Carrascosa González: "El Forum Shopping no es un fenómeno negativo en sí mismo. En efecto, gracias al Forum Shopping las partes pueden elegir "Leyes mejores" y evitar "Leyes peores", lo que tiene sus ventajas" ${ }^{25}$. Un fenómeno que permite al demandante "situar» el litigio ante los tribunales del país de su preferencia, que será, como es lógico, el que le convenga más subjetivamente, en el sentido de que aplicará las normas procesales y sustantivas que más le favorezcan ${ }^{26}$.

37. Desde una perspectiva de estricta tutela procesal, no puede censurarse esta tendencia del actor a buscar el tribunal más favorable a su pretensión, pero sí resulta legítimo "condenar esta elección cuando se ven violentados los derechos del demandado"27. En el caso que nos ocupa, existían contactos razonables entre el litigio y las dos jurisdicciones implicadas, por lo que el acto de acudir a una u otra no puede calificarse por sí solo de fraudulento.

38. Pero sí lo es el hecho de instar un segundo proceso en España, a sabiendas de la pendencia del primero en Estados Unidos. Máxime cuando en este procedimiento se omite información determinante sobre el domicilio de la demandada, provocando con ello su desconocimiento del proceso y la emisión de una sentencia en rebeldía procesal. Esta ausencia forzosa -forzada- en el proceso tiene además una consecuencia de especial gravedad: privar a la demanda de la posibilidad procesal de solicitar la suspensión del procedimiento por litispendencia internacional, evitando así no sólo la sustanciación de un proceso donde no puede defenderse sino también la emisión de una sentencia en España que pueda suponer un obstáculo ulterior a sus intereses.

\footnotetext{
${ }^{22}$ Derecho Procesal Civil. I. El proceso de declaración. Parte General, Colex, Madrid, 2010, p. 673.

${ }^{23}$ Así lo ratifica la jurisprudencia del Tribunal Supremo cuando subraya que el carácter extraordinario de este «recurso» radica en el hecho de que "vulnera el principio riguroso y casi absoluto de irrevocabilidad de los fallos que hayan ganado firmeza", siendo ésa la razón de que "la interpretación de los supuestos que lo integran haya de realizarse con criterio restrictivo" (entre las más recientes, SSTS núm. 215/2017 de 4 abril, RJ 2017 2665; núm. 711/2015, de 16 de diciembre, RJ 2016 270; núm. 822/2013, de 19 de diciembre 2013\8410; núm. 788/2012, de 14 de diciembre, RJ 2013\918; y núm. 634/2012, de 23 de octubre, RJ 2013\1541).

${ }^{24}$ Sentencia núm. 158/1987, de 20 de octubre (RTC 1987\158).

25 "La ley aplicable al divorcio en Europa: el futuro Reglamento Roma III", Cuadernos de Derecho Transnacional, marzo 2009, Vol. 1, N 1 , p. 47.

${ }^{26}$ A.L. Calvo Caravaca, "Armas legales contra la crisis económica. Algunas respuestas del Derecho Internacional Privado", Cuadernos de Derecho Transnacional, marzo 2013, Vol. 5, № 1, p. 42.

27 A. Agullar Domínguez, "La delgada línea...", p. 78.
} 
39. En efecto, y a mayor abundamiento, esta conducta fraudulenta desde la perspectiva de la buena fe procesal, puede tener otra consecuencia censurable: que la sentencia dictada en España, prácticamente al mismo tiempo que la emitida en Estados Unidos, llegue a constituir un motivo de oposición al reconocimiento de la segunda en nuestro país, sobre la base del artículo 46.1.d) de la Ley 29/2015, de 30 de julio, de cooperación jurídica internacional en materia civil ${ }^{28}$.

40. Se trata de un aspecto enormemente interesante, que sin embargo no procede abordar aquí, puesto que no constituye el objeto de la sentencia analizada. No obstante, resulta oportuno dejarla apuntada, por su considerable interés jurídico, ya que llegado el caso, podría plantearse la cuestión de la eventual eficacia que pudiera tener en España la sentencia que se dicte en Estados Unidos, puesto que aun existiendo el mencionado motivo de denegación del artículo 46.1.d), la -probada- mala fe del demandante en el proceso sustanciado en España podría neutralizar la efectividad de la sentencia española como motivo de oposición a la resolución norteamericana. Y a la inversa, los efectos que pudiera desplegar la sentencia española en aquel país también pueden verse mermados -o eliminados- por la existencia de otra decisión judicial emitida en él. De este modo, podría darse plantearse el caso de dos resoluciones judiciales claudicantes, únicamente eficaces en sus respectivos países, una situación nada deseable y desafortunadamente, frecuente en el ámbito del Derecho internacional privado.

41. En definitiva, resulta incuestionable que el forum shopping puede provocar efectos colaterales negativos ${ }^{29}$, pero lo que este asunto evidencia no es un mero uso de esta institución en beneficio propio, sino que se aprecia un abuso desde el momento en que se utiliza como mecanismo para provocar una duplicidad de procesos. Esta maniobra del demandante convierte al forum shopping en un vehículo para el fraude, apreciación que refuerza su voluntario ocultamiento de un dato procesal tan esencial como el domicilio de la demandada. Y pese a que reiteramos nuestra convicción de que el forum shopping no resulta censurable per se, en el presente caso es obligado admitir su condición de «causa causae» de la maquinación fraudulenta, toda vez que el ocultamiento intencionado del domicilio de la demandada para provocar una rebeldía procesal sólo pudo realizarse al amparo de la opción de litigar en España que al demandante otorgó nuestro sistema de competencia judicial internacional.

28 “Artículo 46. Causas de denegación del reconocimiento. 1. Las resoluciones judiciales extranjeras firmes no se reconocerán: (...) d) Cuando la resolución fuera inconciliable con una resolución dictada en España”. Sobre el concepto de «inconciliabilidad» y su contenido como motivo de oposición al reconocimiento o exequátur, vid. F. GASCón INCHAUSTI, "Reconocimiento y ejecución de resoluciones judiciales extranjeras en la Ley de cooperación jurídica internacional en materia Civil", Cuadernos de Derecho Transnacional, octubre 2015, Vol. 7, № 2 p. 182 y 185.

${ }^{29}$ A.L. Calvo Caravaca y J. Carrascosa González, “ob.cit...”, ob. cit., p. 47. 